\title{
Short Communication: Elevated Concentrations of Oleic Acid and Long- Chain Fatty Acids in Milk Fat of Multiparous Subclinical Ketotic Cows
}

\author{
Y. N. T. Van Haelst, ${ }^{\star}$ A. Beeckman, ${ }^{*}$ A. T. M. Van Knegsel, $†$ and V. Fievez ${ }^{* 1}$ \\ *Laboratory for Animal Nutrition and Animal Product Quality, Faculty of Bioscience Engineering, Ghent University, Proefhoevestraat 10 , \\ 9090 Melle, Belgium \\ †Adaptation Physiology Group, Wageningen Institute of Animal Sciences, Wageningen University, PO Box 338, $6700 \mathrm{AH}$ Wageningen, \\ the Netherlands
}

\section{ABSTRACT}

The objective of this study was to determine whether concentrations of specific fatty acids in milk fat are a candidate for the early detection of subclinical ketosis. The case study included multiparous cows fed a lipogenic diet or a mixed glucogenic:lipogenic diet during the first $9 \mathrm{wk}$ of lactation. Milk fatty acid profiles of cows classified as healthy $(\mathrm{n}=8)$ or as subclinically ketotic $(\mathrm{n}=8)$ based on a blood plasma $\beta$-hydroxybutyrate threshold concentration of $1.2 \mathrm{mmol} / \mathrm{L}$ were compared. Subclinically ketotic cows showed an elevated proportion of C18:1 cis-9 in milk fat during the whole registration period.

Key words: dairy cow, subclinical ketosis, milk fatty acid

At the onset of lactation, the dairy cow must accommodate a tremendous increase in energy demand by the mammary gland for milk production. This is realized partly by increasing feed intake and partly by fat mobilization from adipose tissue. However, excessive fat mobilization can induce an imbalance in hepatic carbohydrate and fat metabolism, characterized by elevated concentrations of ketone bodies (BHBA, acetoacetate, and acetone), a state called hyperketonemia (Goff and Horst, 1997; Nielsen and Ingvartsen, 2004). Hyperketonemia has an economical effect in its clinical manifestation (ketosis), through a decreased milk production and greater risk of periparturient diseases such as mastitis (Duffield, 2000). Detection of the preclinical stage of ketosis should allow early intervention, which is beneficial both from an economical and an animal welfare point of view. Current detection methods are based on the measurement of ketone bodies in body fluids, and recent research has been focused toward their detection in milk because of its convenience of

Received May 19, 2008.

Accepted August 18, 2008.

${ }^{1}$ Corresponding author: veerle.fievez@UGent.be sampling (Enjalbert et al., 2001; De Roos et al., 2007). Because mobilization of adipose tissue precedes ketosis development (Reist et al., 2003) and mobilized fatty acids (FA) are incorporated in milk fat, changes in milk FA composition might be an earlier indicator of hyperketonemia.

Data and samples originated from the experiment of Van Knegsel et al. (2007) assessing energy balance from $3 \mathrm{wk}$ before the expected calving date to $9 \mathrm{wk}$ postpartum. The original aim of the experiment was to study strategies to decrease the severity of the negative energy balance at the beginning of lactation. Of 76 cows (both multiparous and primiparous) in the experiment of Van Knegsel et al. (2007), 22 (3 glucogenic, 11 lipogenic, 8 mixed lipogenic:glucogenic; cow diet) showed blood plasma BHBA concentrations beyond the threshold of $1.2 \mathrm{mmol} / \mathrm{L}$ in the first 9 wk postpartum. Because the dietary strategy based on a glucogenic concentrate demonstrated lower plasma NEFA, BHBA, and liver triacylglycerol concentrations, this treatment was excluded for the current study. The 2 other dietary strategies did not systematically affect the former parameters.

Cows received forage ad libitum (prepartum: grass silage:corn silage:wheat straw, 450:450:100; postpartum: grass silage:corn silage:chopped alfalfa hay:rapeseed meal, 484:449:33:33; proportions on DM basis) supplied with a lipogenic $(\mathrm{n}=25)$ or a mixed glucogenic:lipogenic concentrate $(\mathrm{n}=24)$ in amounts varying with parity and lactation week. Based on the realized feed intake, starch: 104 and $179 \mathrm{~g} / \mathrm{kg}$ of DM, crude fat: 50 and 41 $\mathrm{g} / \mathrm{kg}$ of $\mathrm{DM}$ and, net energy: 6.81 and $6.84 \mathrm{MJ} / \mathrm{kg}$ of DM [according to the Belgian-Dutch system (VEM) of net energy for lactation; Van Es, 1975] were calculated for the lipogenic and glucogenic:lipogenic diet, respectively.

Body condition was scored ( 1 to 5 scale) in wk $-3,1$, 4 , and 8 relative to the week of calving. Energy balance was calculated per week according to the Belgian-Dutch system (VEM) of net energy for lactation system as described by Van Knegsel et al. (2007). Weekly collected 
jugular blood was analyzed for BHBA and NEFA with the Ranbut and FA 115 kits, respectively (Van Knegsel et al., 2007; Randox Laboratories Ltd., Crumlin, UK), on a Unicel DxC 600 analyzer (Beckman Instruments B.V., Mijdrecht, the Netherlands). Milk production was recorded daily. Milk composition variables (fat, protein, and SCC: ISO 9622, ISO, 1999; Melkcontrolestation, Zupthen, the Netherlands) were monitored 4 times per week. Pooled Wednesday evening and Thursday morning milk samples (50/50, wt/wt) were analyzed for milk FA after extraction, methylation, and GLC as described by Lourenço et al. (2005) and were expressed as grams per $100 \mathrm{~g}$ of FA methyl esters (FAME). Proportions of short-chain FA, medium-chain saturated FA (MCSFA), and long-chain FA (LCFA) were calculated as the sum of $\mathrm{C} 4: 0, \mathrm{C} 6: 0$, and $\mathrm{C} 8: 0 ; \mathrm{C} 10: 0, \mathrm{C} 12: 0$, and $\mathrm{C} 14: 0$; and C18:0, total C18:1, total C18:2, total C18:3, C20:0, and total $\mathrm{C} 20: 1$ proportions in milk fat, respectively.

To compare the milk FA profile, 2 groups have been created from the data set by selecting cows based on plasma BHBA concentrations (Table 1). Multiparous cows with plasma BHBA concentration above a threshold value of $1.2 \mathrm{mmol} / \mathrm{L}(\mathrm{n}=8)$ in either wk 3,4 , or 5 in lactation, but not showing elevated BHBA concentrations in other weeks, were classified as subclinically ketotic (SCK).The control group consisted of cows $(\mathrm{n}=8)$ showing normal plasma BHBA concentration $(<1.2 \mathrm{mmol} / \mathrm{L})$ during the whole registration period and were selected from the data set to approach a similar distribution of milk yield, dietary management, crude fat intake, parity, and SCC, in decreasing order of importance (Table 1).

Milk and blood variables were compared over 3 -wk periods: (i) wk 3 to 5 in lactation, referred to as the diagnosis period; (ii) a postdiagnosis period, which was 4 wk later; and (iii) a prediagnosis period, which was 2 wk earlier except for 1 cow diagnosed SCK in wk 3 of lactation. Prediagnosis values for this cow referred to the second lactation week.

Statistical analysis was performed with SPSS 12.0 (SPSS Inc., Chicago, IL) using a nonparametric t-test for group comparison and a 1-way ANOVA for period comparison.

No differences in BCS were measured between groups, and the overall mean BCS scores of both groups were $3.31 \pm 0.1,3.18 \pm 0.1,2.88 \pm 0.09$, and $2.86 \pm 0.09$ in wk $-3,1,4$, and 8 relative to calving, respectively. The SCK-diagnosed cows tended to have a more negative energy balance in the prediagnosis period [SCK: -274 \pm 47 , control: $\left.-150 \pm 40, \mathrm{~kJ} /\left(\mathrm{kg}^{0.75} \cdot \mathrm{d}\right) ; P=0.099\right]$ and had a significantly lower negative energy balance in the diagnosis period compared with control cows [SCK: $-138 \pm 23$, control: $-61 \pm 36, \mathrm{~kJ} /\left(\mathrm{kg}^{0.75} \cdot \mathrm{d}\right) ; P$ $=0.048]$.

Milk FA proportions, given in Figure 1, indicate an increase in MCSFA and a decrease in LCFA, particularly C18:1 cis-9 from the prediagnosis to diagnosis and from the diagnosis to postdiagnosis period. This is in line with the effect of lactation stage on milk FA profile reviewed by Palmquist et al. (1993). In none of the 3 registration periods, differences occurred between the 2 groups in milk fat content and milk fat:protein ratios (data not shown).

There is a tendency for greater LCFA proportions in SCK-diagnosed cows. Yet, significantly greater milk LCFA proportions, combined with lower MCSFA proportions, were measured at the week of diagnosis only. The C18:1 cis-9 proportion in milk fat (g/100 g of FAME) was $3.46,4.42$, and 2.08 units greater in SCKdiagnosed cows in the pre-, diagnosis, and postdiagnosis period, although no differences in plasma BHBA were observed in the pre- and postdiagnosis period. Greater proportions of LCFA and especially C18:1 cis-9 in SCKdiagnosed cows could originate from greater body fat

Table 1. Average milk production $(\mathrm{kg} / \mathrm{d})$ in different defined periods and distribution (number of cows) in parity, dietary strategy, and SCC for groups of control and subclinical ketosis-diagnosed (SCK) cows included in this case study ${ }^{1}$

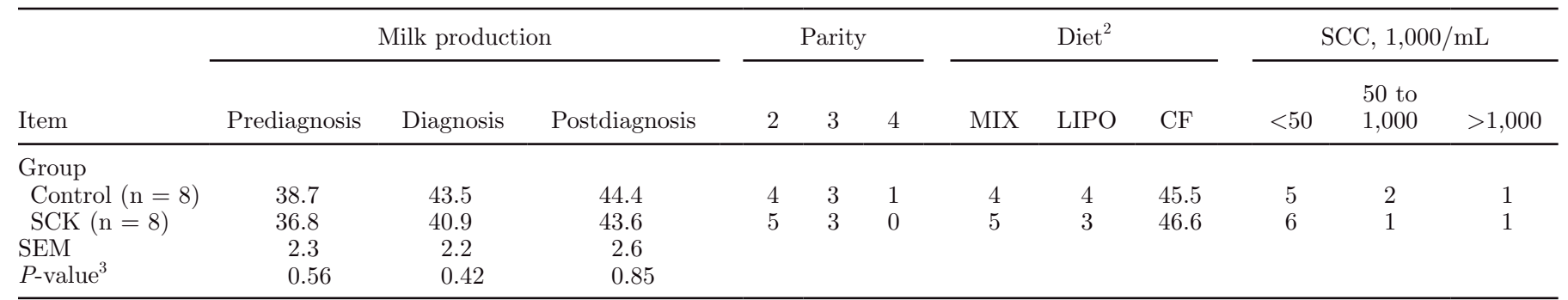

${ }^{1}$ The diagnosis period is the week associated with increased blood BHBA concentrations $(>1.2 \mathrm{mmol} / \mathrm{L})$ in SCK cows and wk 4 of control cows. The pre- and postdiagnosis period is 2 wk earlier or 4 wk later, respectively, except for 1 SCK cow with wk 2 as prediagnosis and wk 3 as diagnosis period. The SCC values were as detected in milk in wk 4.

${ }^{2} \mathrm{MIX}=$ mixed lipogenic:glucogenic diet; $\mathrm{LIPO}=$ lipogenic diet; $\mathrm{CF}=$ crude fat content $(\mathrm{g} / \mathrm{kg}$ of DM).

${ }^{3} P$-value based on 1-way ANOVA with milk production as dependent variable. 


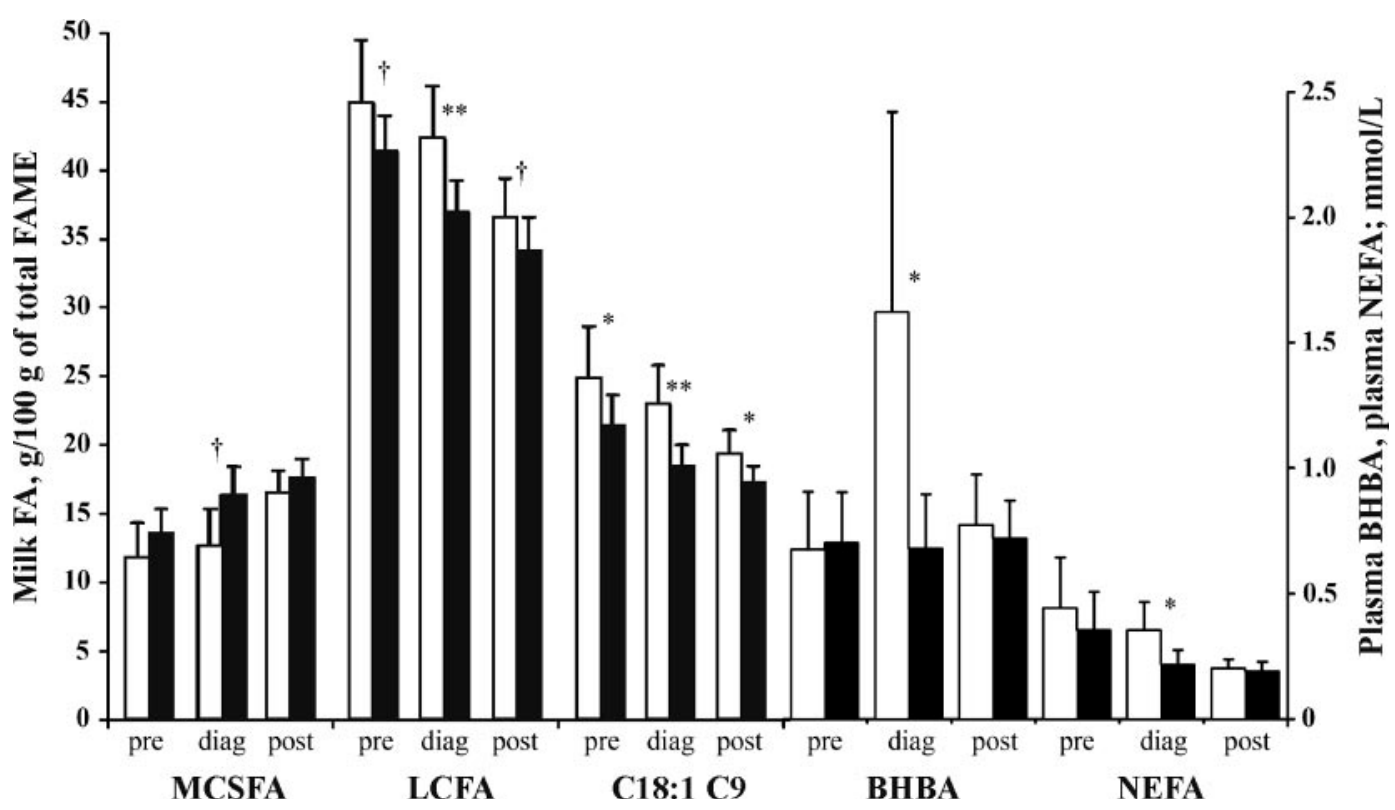

Figure 1. Milk fatty acid (FA) proportions, blood plasma NEFA, and BHBA concentration in subclinical ketosis (SCK)-diagnosed cows (white bars, $\mathrm{n}=8$ ) and healthy cows (black bars, $\mathrm{n}=8$ ) in relation to the period around diagnosis. Pre = prediagnosis; diag $=$ diagnosis; post $=$ postdiagnosis period. Error bars are the equivalent of 1 standard deviation. The $t$-test scores, indicating differences between SCK and control cows, are given in asterisks: ${ }^{*} P<0.05,{ }^{*} P<0.01$, ${ }^{* *} P<0.001$, †tendency, $P<0.1$. Medium-chain saturated FA $(\mathrm{MCSFA})=\mathrm{C} 10: 0+\mathrm{C} 12: 0+$ C14:0; long-chain FA $($ LCFA $)=$ C18:0 + total C18:1 + total C18:2 + total C18:3 + C20:0 + total C20:1. FAME = fatty acid methyl esters.

mobilization. Indeed, the major NEFA released during this process are $\mathrm{C} 16: 0, \mathrm{C} 18: 0$, and $\mathrm{C} 18: 1$ cis-9, with the latter being the most abundant (Leroy et al., 2005). Greater fat mobilization was associated with a more negative energy balance in the prediagnosis and diagnosis period and a greater blood NEFA concentration $(P<0.01)$ in the SCK group in the diagnosis period (SCK group: $0.36 \pm 0.04$, control group: $0.22 \pm 0.02$, $\mathrm{mmol} / \mathrm{L})$. No differences in blood NEFA concentrations were visible in the prediagnosis period, but stress-related or diurnal fluctuations in NEFA concentrations may have masked results (Andersson, 1988). This might include another advantage of milk FA analysis, because milk better integrates diurnal changes.

Because milk LCFA originate both from fat mobilization and diet, these milk FA can be strongly influenced by the amount of LCFA in the diet. Similar differences in the milk fat $\mathrm{C} 18: 1$ cis-9 proportions as observed between SCK and control cows have been induced through dietary modification, such as supplementation of linseed, sunflower, and rape oil seeds (4.0, 5.2, and 10.6 units greater in the supplemented groups compared with the nonsupplemented control, g/100 g of total FA; e.g., Chilliard and Ferlay, 2004). In the current study, a similar distribution in dietary management and crude fat intake of the control and SCK group has been attempted (Table 1). Moreover, palmitic acid, being the major FA in the dietary fat supplement, was omitted from the milk FA analysis. Hence, it is unlikely that changes between the control and SCK group are of dietary origin in this experiment. Milk MCSFA, LCFA, C18:0, and C18:1 cis-9 secretions, estimated as milk fat content multiplied with FAME proportions and corrected for glycerol, did not differ, except for a tendency in greater C18:1 cis-9 secretion in SCK cows compared with control cows in the diagnosis period (0.36 vs. 0.29 $\mathrm{kg} / \mathrm{d}, P=0.07)$.

In conclusion, elevated proportions of $\mathrm{C} 18: 1$ cis-9 are visible in milk fat $2 \mathrm{wk}$ before the SCK diagnosis, making it an interesting trait for SCK prediction. Yet, concentrations deduced from this experiment should only be used within the constraints of the current experiment, because variations of $\mathrm{C} 18: 1$ cis-9 milk fat proportions are affected by, for example, lactation stage and feed composition. A wider experiment or metaanalysis assessing the relationship between SCKdiagnosed and healthy cows in relationship to lactation stage and dietary fat content could assess the validity of milk C18:1 cis-9 concentrations as a diagnostic tool for predicting SCK.

\section{ACKNOWLEDGMENTS}

We would like to acknowledge the Institute for the Promotion of Innovation by Science and Technology in Flanders (Brussels, Belgium) for their financial support. 


\section{REFERENCES}

Andersson, L. 1988. Subclinical ketosis in dairy cows. Vet. Clin. North Am. Food Anim. Pract. 4:233-251.

Chilliard, Y., and A. Ferlay. 2004. Dietary lipids and forages interactions on cow and goat milk fatty acid composition and sensory properties. Reprod. Nutr. Dev. 44:467-492.

De Roos, A. P. W., H. J. C. L. van den Bijgaart, J. Hørlyk, and G. de Jong. 2007. Screening for subclinical ketosis in dairy cattle by fourier transform infrared spectrometry. J. Dairy Sci. 90:17611766.

Duffield, T. 2000. Subclinical ketosis in lactating dairy cattle. Vet. Clin. North Am. Food Anim. Pract. 16:231-253.

Enjalbert, F., M. C. Nicot, C. Bayourthe, and R. Moncoulon. 2001. Ketone bodies in milk and blood of dairy cows: Relationship between concentrations and utilization for detection of subclinical ketosis. J. Dairy Sci. 84:583-589.

Goff, J. P., and R. L. Horst. 1997. Physiological changes at parturition and their relationship to metabolic disorders. J. Dairy Sci. $80: 1260-1268$

ISO (International Organization for Standardization). 1999. Whole milk. Determination of milk fat, protein and lactose contentGuidance on the operation of mid-infrared instruments; ISO 9622. ISO, Geneva, Switzerland.

Leroy, J. L. M. R., T. Vanholder, B. Mateusen, A. Christophe, G. Opsomer, A. de Kruif, G. Genicot, and A. Van Soom. 2005. Nonesterified fatty acids in follicular fluid of dairy cows and their effect on developmental capacity of bovine oocytes in vitro. Reproduction 130:485-495.

Lourenço, M., B. Vlaeminck, M. Bruinenberg, D. Demeyer, and V. Fievez. 2005. Milk fatty acid composition and associated rumen lipolysis and fatty acid hydrogenation when feeding forages from intensively managed or semi-natural grasslands. Anim. Res. $54: 471-484$.

Nielsen, N. I., and K. L. Ingvartsen. 2004. Propylene glycol for dairy cows. A review of the metabolism of propylene glycol and its effects on physiological parameters, feed intake, milk production and risk of ketosis. Anim. Feed Sci. Technol. 115:191-213.

Palmquist, D. L., A. D. Beaulieu, and D. M. Barbano. 1993. ADSA Foundation Symposium: Milk fat synthesis and modification. Feed and animal factors influencing milk fat composition. J. Dairy Sci. 76:1753-1771.

Reist, M., D. Erdin, D. von Euw, K. Tschuemperlin, H. Leuenberger, C. Delavaud, Y. Chilliard, H. M. Hammon, N. Kuenzi, and J. W. Blum. 2003. Concentrate feeding strategy in lactating dairy cow: Metabolic and endocrine changes with emphasis on leptin. J. Dairy Sci. 86:1690-1706.

Van Es, A. J. H. 1975. Feed evaluation for dairy cows. Livest. Prod. Sci. 2:95-107.

Van Knegsel, A. T. M., H. van den Brand, J. Dijkstra, W. M. van Straalen, R. Jorritsma, S. Tamminga, and B. Kemp. 2007. Effect of glucogenic vs. lipogenic diets on energy balance, blood metabolites, and reproduction in primiparous and multiparous dairy cows in early lactation. J. Dairy Sci. 90:3397-3409. 